\title{
REDES SOCIAIS E IDENTIDADE NACIONAL: A FORÇA DE UM GESTO
}

\author{
SOCIAL NETWORKS AND NATIONAL IDENTITY: \\ THE POWER OF A GESTURE
}

\section{REDES SOCIALES Y LA IDENTIDAD NACIONAL: LA FUERZA DE UN GESTO}

\author{
Célia Maria Ladeira Mota, \\ Doutora, Universidade de Brasília (UnB). \\ cladmota@gmail.com \\ Paulo Henrique Soares de Almeida \\ Mestre, Universidade de Brasília (UnB). \\ pauloalmmeida@gmail.com
}

\section{Resumo:}

Este artigo analisa o episódio que ocorreu com o jogador brasileiro Daniel Alves, que durante uma partida do seu time, o Barcelona, em 27 de abril de 2014, recebeu uma banana atirada a ele por um torcedor do Villarreal. Surpreendeu a resposta de Daniel Alves, que pegou a banana e comeu. $\mathrm{O}$ gesto gerou um movimento nas redes sociais e a campanha com a hashtag "somos todos macacos", publicada no Instagram, provocou no Brasil uma discussão sobre a representação da identidade brasileira e crítica ao racismo. Neste estudo, examinamos as reações do episódio tendo como base o conceito de representações sociais tal como destacado por Moscovici (2011) e metodologia da hermenêutica de profundidade, conforme proposta por Thompson (1995).

Palavras-chave: Identidade Nacional. Redes sociais. Racismo.

\begin{abstract}
:
This article analyzes the episode that occurred with the Brazilian soccer player Daniel Alves, who during a match of his team, Barcelona, on April 27, 2014, received a banana thrown to him by a fan of Villarreal. It was a surprise the reaction of Daniel Alves, who took the banana and ate it. The gesture generated a movement in social networks and the campaign with the hashtag "we are all monkeys", published in Instagram, caused in Brazil a big discussion of the representation of Brazilian identity and criticism of racism. In this study, we examined the reactions caused by the episode based on the concept of social representations as highlighted by Moscovici (2011) and methodology of depth hermeneutics, as proposed by Thompson (1995).
\end{abstract}

Keywords: National identity. Social networks. Racism.

\section{Resumen:}

Este artículo analiza el episodio que se sucedió con el jugador brasileño Daniel Alves, que durante un juego de su equipo, Barcelona, el 27 de abril de 2014, recibió una banana jugada a 
él por un forofo del Villarreal. Sorprendido la respuesta de Daniel Alves, que se llevó el banana y se la comió . El gesto generó un movimiento en las redes sociales y la campaña con el hashtag "todos somos macacos", publicado en Instagram, causou en Brasil una discusión sobre la representación de la identidad brasileña y la crítica del racismo. En este estudio se analizaron las reacciones causadas por el episodio basado en el concepto de representaciones sociales destacado por Moscovici (2011) y la metodología de la hermenéutica de profundidad de acuerdo con Thompson (1995).

Palabras clave: Identidad Nacional. Redes sociales. Racismo.

\section{INTRODUÇÃO}

A identidade, antes ligada ao conceito de nação, se globalizou, mas deteve no núcleo um ator social que o relaciona aos demais: o cidadão. A cidadania, que vem da consciência da identidade com seus direitos e deveres, faz frente à sociedade em que se insere, seja na rede da internet, no país ou na rua. Além desses elos que vivem das tradições, mitos e crenças nacionais, a nação compartilha marcos culturais, sociais e políticos que criam nos sujeitos correntes de identidade, de pertencimento e de grupo. E neste cenário globalizado também está inserido o povo brasileiro, com sua herança cultural e história.

Este artigo analisa o episódio que ocorreu com o jogador brasileiro Daniel Alves, quando durante uma partida do seu time, o Barcelona, em 27 de abril de 2014, recebeu uma banana atirada a ele por um torcedor do Villarreal. Surpreendeu, porém, a resposta de Daniel Alves, que pegou a banana e comeu. O gesto gerou um movimento nas redes sociais e a campanha com a hashtag "somos todos macacos", publicada no Instagram, provocou no Brasil uma discussão sobre a representação da identidade brasileira e crítica ao racismo.

Neste estudo, examinamos as reações provocadas pelo episódio tendo como base o conceito de representações sociais tal como destacado por Moscovici (2011) e metodologia da hermenêutica de profundidade, conforme proposta por Thompson (1995). O episódio em análise se insere também na proposta do movimento antropofágico, defendido pelo escritor Oswald de Andrade (1928), que se tornou o documento do modernismo brasileiro. Com o objetivo de repensar a dependência cultural brasileira, o movimento antropofágico ironizava a submissão do Brasil aos países desenvolvidos e propunha a deglutição ou o processamento da cultura estrangeira e não apenas a imitação do que vem de fora. 


\section{O MOVIMENTO ANTROPOFÁGICO}

Durante as comemorações do primeiro centenário da independência do Brasil, em 1922, um grupo de jovens escritores, tendo a frente Oswald e Mário de Andrade, aos quais se uniram pintores, como Tarsila do Amaral e Di Cavalcanti, e músicos como Heitor VillaLobos, lançaram um movimento que buscava fundar a nação brasileira em um ato de ruptura em relação à Europa. Reunidos no Teatro Municipal de São Paulo, onde se festejava uma semana de arte moderna, esses intelectuais rasgaram simbolicamente um livro de Camões para marcar assim a independência cultural do passado colonial europeu. Teve início o modernismo brasileiro por meio de uma revolução estética da linguagem, da arte e de outras formas de expressão artística. Foi o primeiro ato de consciência coletiva e de busca da identidade brasileira. O quadro Abaporu, de Tarsila do Amaral, uma representação de um índio de pés grandes, simbolizou o movimento. A palavra Abaporu, em tupi-guarani, significa "índio que come gente".

Esta revolta modernista assume seu caráter antropofágico de forma simbólica. Comer o inimigo era uma prática dos índios tupis-guarani porque acreditavam que, assim, se alimentavam com as qualidades de suas vítimas. Seguindo este exemplo, os modernistas do século XX propõem devorar a cultura europeia, numa antropofagia cultural que busca acabar com a importação de práticas artísticas e literárias da velha Europa. Esta postura vai permitir aos modernistas a busca de expressão da brasilidade, redescobrindo o barroco mineiro e dando a ele novos traços, pintando o homem brasileiro das cidades e do sertão, assim como as paisagens proletárias de São Paulo. Até mesmo o surrealismo, então em voga especialmente na França, será antropofagicamente deglutido pelos modernistas brasileiros, que buscam transformar a realidade pelo imaginário.

Um personagem típico desse surrealismo à brasileira foi Macunaíma, criado por Mário de Andrade. Macunaíma era um índio de pele negra e olhos azuis - uma mistura de raças que deu origem ao homem brasileiro - e que foi considerado um herói sem caráter. Ele é preguiçoso, prefere dormir numa rede, mas aventura-se pela floresta amazônica, seduzindo a rainha das amazonas.

Outro autor dessa época, Oswald de Andrade, já havia lançado as bases do movimento antropofágico com o seu Manifesto da Poesia Pau-Brasil, exaltando a originalidade nativa e os estados brutos da alma coletiva do homem brasileiro. Segundo Oswald de Andrade, o bacharelismo, o gabinetismo e o academismo, as frases feitas da sabedoria nacional, servem de matéria prima para a poesia Pau Brasil, "que decompõe o arcabouço intelectual da 
sociedade brasileira para retomar a originalidade nativa e fazer dela uma arte nacional exportável, reconciliando, no dizer do escritor, a floresta com a escola" (ANDRADE, 1924).

\section{FORMAÇÃO DO BRASILEIRO}

O mérito do movimento antropofágico foi o de centrar o olhar para a realidade étnica do brasileiro. De acordo com o antropólogo Darcy Ribeiro (2010), os brasileiros se encontram na categoria de povos novos, oriundos do cruzamento de índios, brancos europeus e negros africanos, produzindo uma diversidade de fenotipia que nos caracteriza. Durante séculos, os filhos de portugueses com índias falavam a língua geral, com base no tupi. Depois, com a chegada dos escravos negros, o português aprendido ao som dos gritos dos capatazes foi se tornando a língua materna do país. A mestiçagem entre os portugueses e os africanos gerou um tipo muito comum, o mulato.

Nas Américas, existem quatro configurações histórico-culturais de povos, nitidamente diferenciados por seus respectivos processos de formação: os povos testemunho, os povos novos, os povos transplantados e os povos emergentes. Os povos testemunho, conforme Darcy Ribeiro (2010), resultaram do choque do invasor europeu com as altas civilizações maia, asteca e incaica, e os remanescentes dessas culturas não se miscigenaram com os espanhóis, restando como memória ou testemunho das civilizações dizimadas. Outra categoria é a de povos emergentes, uma subdivisão dos povos testemunhos, que reforçam a identidade original das velhas civilizações e procuram recriar novas comunidades em torno dos antigos hábitos culturais.

Os povos transplantados é uma categoria que explica a implantação de grupos de colonizadores que se estabeleceram nos Estados Unidos e no Canadá, aí constituindo núcleos habitacionais que não se misturaram com os índios nativos já existentes naqueles países. Os povos novos, por sua vez, surgiram na confluência entre índios tribais, negros escravos e brancos ibéricos, aliciados nas plantações tropicais para o trabalho nas minas de metais preciosos ou na exploração florestal. São povos que fizeram surgir um ente étnico novo, que não tendo passado para se orgulhar, se voltaram para a construção do futuro e foram constituindo o que passou a se chamar de brasileiro em meados do século XIX.

O antropólogo Darcy Ribeiro destaca que uma herança cultural que herdamos da Europa foi desde sempre e ainda é o racismo, "como arma principal do arsenal ideológico europeu de dominação colonial" (RIBEIRO, 2010, p.87). O processo foi sutil, mas ao mesmo tempo brutal. O homem branco assumiu o papel de agente civilizador dos países a serem 
colonizados, porque seriam habitados por sub-raças, que deveriam ser submetidas ao seu poder. "O racismo latino-americano é, como se vê, fruto europeu de exportação, que, transplantado aqui, vicejou que foi um horror" (RIBEIRO, 2010, p.88).

\section{RACISMO À BRASILEIRA}

No século XIX, algumas teorias racistas europeias chegaram ao Brasil por meio dos viajantes. Entre eles o conde Gobineau, que residiu no Rio de Janeiro como cônsul da França. Para Gobineau (1856), o maior problema racial residia na miscigenação que ele considerava um atentado à hierarquização entre raças, vistas e classificadas como pertencendo a espécies diferentes de seres humanos. Assim, caracterizou o "mulato" como um ser degenerado pela dificuldade de ser classificado, já que não seria branco ou negro, mas uma mistura "que vai apagando rapidamente as melhores qualidades do branco, do negro e do índio, criando um ser indefinido, híbrido, deficiente em energia física e mental" (AGASSIZ apud DA MATTA, 1984, p.40).

Considerado o representante por excelência da miscigenação no Brasil, o mulato passou a ser exaltado por Gilberto Freyre com sua teoria do cadinho das três raças. Ele é o paradigma do "povo moreno", a forma como Darcy Ribeiro classifica o brasileiro. Por ser um intermediário e a síntese dos opostos, adquiriu um valor positivo nas primeiras teorias antropológicas de estudiosos brasileiros, durante o século XX. E esta definição vai tornar o racismo um instrumento de diferenciação étnica de difícil categorização.

O racismo à americana coloca em contraste brancos e negros. No Brasil, no entanto, este dualismo se torna mais problemático. Na rígida divisão social do Brasil colonial, o branco era o senhor e o negro o escravo. E o mulato? Era o filho do homem branco com a mulher negra, um filho da casa, na relação casa-grande e senzala. Criou-se o mito da democracia racial.

O mito, que explica que somos todos, os brasileiros, frutos de uma intensa triangulação entre brancos, negros e índios, apagou, de certa forma, a discriminação que existia, de forma velada, numa sociedade hierarquizada. Como afirma Da Matta, "a mistura de raças foi um modo de esconder a profunda injustiça social contra negros, índios e mulatos, pois, situando no biológico uma questão profundamente social, econômica e política, deixava de lado a problemática mais básica da sociedade” (DA MATTA, 1984, p.46).

Um caminho para a superação foi por meio de uma lei, que assegurasse a todos os brasileiros o direito básico de toda igualdade: o direito de ser igual perante a lei. O primeiro 
passo para isso se deu em 1951, quando foi aprovada a lei 1390, mais conhecida como Lei Afonso Arinos. Essa lei proibia a discriminação racial no país, mas não estabelecia punições mesmo em casos explícitos de discriminação em locais de emprego, escolas e serviços públicos. Em 1989, uma nova lei, a de número 7716, conhecida como Lei Caó, porque proposta pelo advogado Carlos Alberto Oliveira dos Santos, determinou a igualdade racial e tornou crime a discriminação. Pela lei, o crime de racismo é inafiançável, mas a lei faz gradações especificando atitudes que poderiam ser consideradas como racismo.

Uma destas atitudes previstas na lei é a da injúria racial. Ela ocorre quando são ditas ou expressas ofensas a pessoas por causa da sua cor de pele. É o que acontece quando um negro ou mulato é chamado de "macaco". Esse exemplo ocorre em vários casos no futebol, em que jogadores foram ofendidos por essa palavra e alguns entraram com processo. No caso, os infratores são julgados pelo crime de injúria racial, onde há a lesão da honra subjetiva da vítima.

Já o racismo é mais grave, considerado como um crime inafiançável e imprescritível. Para o crime ser considerado como racismo, tem que menosprezar a raça de alguém, seja por impedimento de acesso a determinado local ou negação de emprego baseado na raça da pessoa. Como exemplo, pode-se considerar o impedimento de matrícula de uma criança em uma escola por ela ser negra. Resumidamente, o racismo impede a prática de exercício de um direito que a pessoa tenha. A injúria racial se determina pela ofensa às pessoas por uma questão de raça.

Crime, injúria, menosprezo, o uso da palavra "macaco" se generalizou em relação ao jogador brasileiro não só nos campos de futebol no país como em outros países, como ocorreu com o jogador Daniel Alves, então no Barcelona. No caso do Daniel, a reação à ofensa recuperou o sentido antropofágico de deglutir e transformar em algo positivo alguma discriminação especialmente racial. Isto gerou o movimento "somos todos macacos", que ocupou por meses a discussão em redes sociais e no Instagram.

\section{RACISMO NA REDE}

A popularização das redes sociais está fazendo parte da vida de milhares de pessoas e isto tem causado um grande impacto na sociedade contemporânea, inclusive no Brasil. De acordo com dados divulgados em julho de 2014 pela empresa de pesquisa SurveyMonkey em parceria com a Social@Ogilvy, os brasileiros são os que mais passam tempo nas redes sociais, totalizando 13,8 horas mensais (DÂMASO, 2014). Além disso, de acordo com a 
pesquisa, os brasileiros também estão entre os que mais compartilham conteúdo (71\%), ficando atrás apenas da China (80\%) e de Hong Kong (73\%).

Entre estas redes sociais está o Instagram, uma ferramenta digital que permite ao usuário tirar uma foto, escolher um filtro e depois compartilhá-la em tempo real. Lançado em outubro de 2010, em março de 2014 o aplicativo já havia ultrapassado a marca de 200 milhões de usuários ativos por mês, com 60 milhões de novas imagens postadas por dia (G1, 2014). Além disso, o número de brasileiros nesta rede social também é alto. Já em agosto de 2012, o Ibope Nielsen Online informou que dos 83,4 milhões de brasileiros que tinham acessado a internet no segundo trimestre de 2012, 14,1 milhões acessavam o Instagram (FRAGA, 2012).

Portanto, este estudo não pretende esgotar o tema, mas refletir, em tempo de globalização e mundialização da cultura, de que forma a interação digital nos faz pensar sobre o papel das redes sociais como instrumento para a representação da identidade brasileira e sua influência na construção de uma cidadania mais plena de direitos no Brasil (LADEIRA MOTA \& ALMEIDA, 2014). Para discutir a questão proposta neste artigo, examinamos o episódio de violência cultural que ocorreu com o jogador brasileiro Daniel Alves, que durante uma partida do seu time, o Barcelona, em 27 de abril de 2014, recebeu uma banana atirada a ele por um torcedor do Villarreal, uma agressão racista por causa da cor do jogador. Surpreendeu, porém, a resposta de Daniel Alves, que pegou a banana e comeu. O gesto, repercutido na internet provocou no Brasil uma discussão sobre a representação da identidade nacional e a questão do racismo.

A análise tem como metodologia a hermenêutica de profundidade (HP), conforme proposta por Thompson (1995). Para o autor, a compreensão de mensagens é um processo de autocompreensão e autoformação, em que as pessoas estão engajadas de diversas maneiras e em diferentes profundidades, carregando consigo o potencial para crítica e autocrítica, mesmo que, em determinadas circunstâncias, o potencial crítico do processo de apropriação possa ser limitado e incompleto.

Ao apontar a questão da ideologia, Thompson a coloca como sendo "uma interpretação arriscada, cheia de conflitos e aberta a discussão" (THOMPSON, 1995, p. 410). Para o autor, a interpretação das formas simbólicas como ideológicas pode estimular uma reflexão crítica sobre as relações de poder e dominação da vida social. No entanto, a reflexão crítica não está necessariamente restrita à esfera dos analistas sociais, mas é capaz de transbordar para o campo social, gerando debates e conflitos. Ou seja, os produtos comunicativos não devem ser apenas consumidos pelo grande público, mas também compreendidos. E cabe aos estudiosos da apropriação cotidiana dos produtos da comunicação 
de massa se interessar pela maneira como as pessoas recebem as mensagens do dia-a-dia e ainda examinar as atitudes tomadas por estes receptores.

Ao percorrer o caminho de análise deste estudo, trabalhamos também com o conceito de Representação Social (R.S.) tal como proposto por Moscovici (2011). O autor estuda as R.S. a partir do campo da psicologia social, onde, para ele, elas estão ligadas à alteridade, ou seja, devem ser analisadas não só a partir da questão do indivíduo, mas também da sociedade como um todo. E nesta concepção, as R.S. estão ligadas diretamente com a comunicação. Para o autor, todas as interações humanas, sejam elas entre duas pessoas ou grupos, pressupõem acontecimentos que estão psicologicamente representados em cada um dos participantes. Esses acontecimentos também estão relacionados ao conhecimento, que, segundo Moscovici, nunca é desinteressado, mas sempre produto de um grupo específico.

Moscovici defende que as R.S. não são criadas por um indivíduo isoladamente, mas sim por pessoas e grupos no decurso da comunicação e da cooperação. Elas igualam toda imagem a uma ideia e toda ideia a uma imagem. "Uma vez criadas, as R.S adquirem vida própria, circulam, se encontram, se atraem e se repelem" (MOSCOVICI, 2011, p. 41). E além de situar os indivíduos e os grupos no campo social, permitindo ao mesmo tempo a elaboração de uma identidade coletiva e pessoal, o ato de representar carrega sempre um sentido simbólico. Sendo assim, Moscovici define as R.S. como:

Um sistema de valores, ideias e práticas com uma dupla função: primeiro, estabelecer uma ordem que possibilitará às pessoas orientar-se em seu mundo material e social e controlá-lo; e, em segundo lugar, possibilitar que a comunicação seja possível entre os membros de uma comunidade, fornecendo-lhes um código para nomear e classificar, sem ambiguidade, os vários aspectos de seu mundo e da sua história individual e social, (MOSCOVICI, 2011, p.21).

De acordo com o autor, as R.S. determinam tanto o caráter do estímulo como a resposta que ele incita. "Conhecê-los e explicar o que eles são e o que significam é o primeiro passo em toda análise de uma situação ou de uma relação social” (MOSCOVICI, 2011, p. 100).

\section{ANÁLISE DA PESQUISA}

No episódio com o jogador brasileiro Daniel Alves, a agência de publicidade Loducca se uniu ao atacante brasileiro Neymar, do Barcelona, para criar a campanha. Após Daniel 
Alves comer a banana atirada pelo torcedor do Villarreal, Neymar publicou uma foto no Instagram com o filho David Lucca no colo segurando uma banana (figura 1) e escreveu "Somos todos macacos", em português, inglês e espanhol.

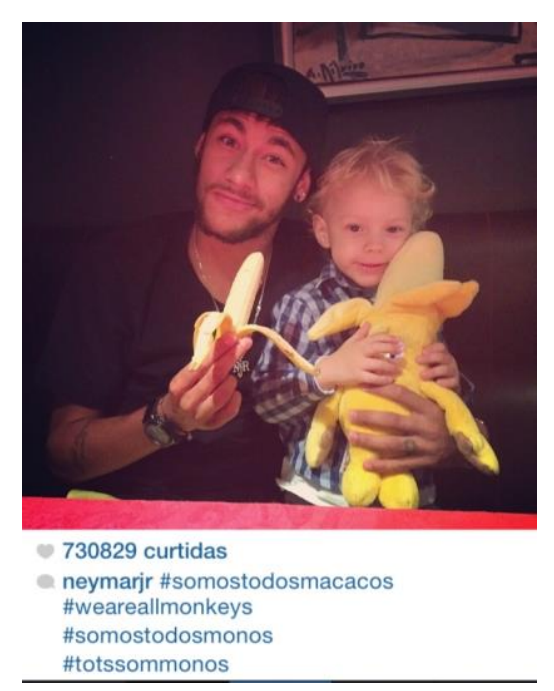

Figura 1: Neymar lança no Instagram a campanha Somos Todos Macacos. Fonte: INSTAGRAM, 2014.

Em seguida, muitos usuários do aplicativo reproduziram a hashtag do protesto que ainda repercute nas redes sociais (figura 2). Até o dia 5 de outubro de 2014, por exemplo, havia 180.893 fotos no Instagram postadas com a legenda \#SomosTodosMacacos e a foto do Neymar com o filho tinha recebido 730.829 curtidas até a data analisada.

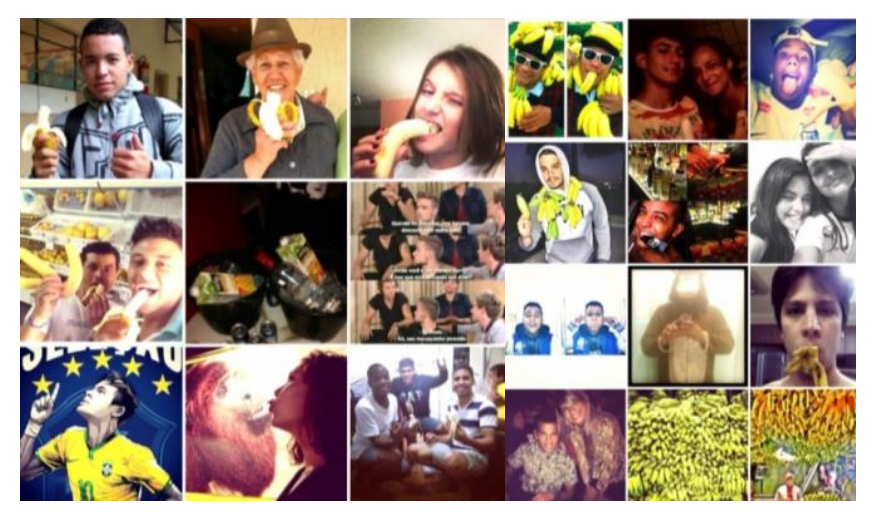

Figura 2: Usuários do Instagram postam fotos com a legenda \#SomosTodosMacacos. Fonte: INSTAGRAM (2014).

No entanto, as questões que destacamos neste estudo são: apesar de muitas pessoas compartilharem a campanha \#SomosTodosMacacos, podemos classificar o movimento como 
uma forma de representação coletiva? É uma maneira de representação da identidade nacional?

Os dados quantitativos sobre a reprodução do conceito \#SomosTodosMacacos no Instagram mostram que a campanha se enquadra dentro do campo de estudo das R.S. tal como proposto por Moscovici (2011), que destaca dois processos importantes para que as representações se formem: a ancoragem e a objetivação. A ancoragem tem a função de classificar, dar nome a alguma coisa ou rotular, enquanto que a objetivação está ligada a reprodução de um conceito a uma imagem, funcionando como um referencial. Ou seja, as R.S "são formadas através de influências recíprocas, através de negociações implícitas no curso das conversações, onde as pessoas se orientam para modelos simbólicos, imagens e valores compartilhados específicos” (MOSCOVICI, 2011, p. 208). De acordo com o autor, o que faz com que uma representação seja partilhada não é o fato de elas serem comuns, mas sim “o fato de seus elementos terem sido construídos através da comunicação e estarem relacionados pela comunicação" (MOSCOVICI, 2011, p. 209).

Neste sentido, segundo Moscovici, as R.S. se apresentam como uma rede de ideias, metáforas e imagens. Elas possuem um aspecto impessoal, sendo ao mesmo tempo representação de outros, pertencentes a outras pessoas ou a outros grupos, como também uma representação pessoal, percebida afetivamente. "Isso significa que as representações compartilhadas, sua linguagem, penetram tão profundamente em todos os interstícios do que nós chamamos de realidade que podemos dizer que elas constituem a identidade, o self, o mercado, as características de uma pessoa, grupo, etc.” (MOSCOVICI, 2011, p. 212).

Por outro lado, de acordo com Moscovici (2011), toda reestruturação de nossas representações e conhecimento depende das interações do momento. É aqui onde o problema da congruência das representações ocorre, no sentido de quais são traduzidas ou não e de como elas são interpretadas. "Nossas ideias e nossas representações são sempre filtradas através do discurso de outros, das experiências que vivemos e das coletividades às quais pertencemos" (MOSCOVICI, 2011, p. 222).

É também neste caminho de interpretação que analisamos a campanha dentro da metodologia de hermenêutica de profundidade (HP), conforme proposta por Thompson (1995). Para o autor, a compreensão de mensagens é um processo de autocompreensão e autoformação, em que as pessoas estão engajadas de diversas maneiras e em diferentes profundidades, carregando consigo o potencial para crítica e autocrítica, mesmo que, em determinadas circunstâncias, o potencial crítico do processo de apropriação possa ser limitado e incompleto. 
Ao estudar a apropriação cotidiana dos produtos da comunicação de massa, além da interpretação do caráter ideológico das mensagens, é preciso analisar também dois aspectos importantes: o contexto sócio-histórico em que as mensagens são produzidas, circuladas e recebidas e as formas de interação.

A campanha, iniciada nas redes sociais, foi inclusive um fato que se transformou em acontecimento jornalístico e que reverberou em jornais impressos, telejornais e sites. O site do Uol (figura 3), por exemplo, publicou uma matéria no dia 27 de abril de 2014 com o título "Neymar apoia Daniel Alves após lateral comer banana: somos todos macacos".

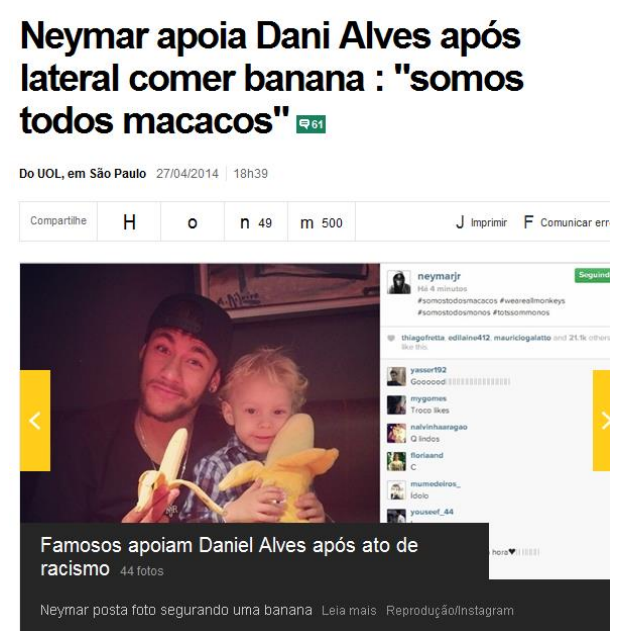

Figura 3: A campanha reverberou em jornais impressos, telejornais e sites. Fonte: UOL (2014).

No entanto, apesar de um grande número de pessoas compartilharem a ideia do movimento, muitos, porém, acusaram a agência Loducca de racismo e disseram que o protesto "Somos todos macacos" não servia como instrumento para a compreensão da identidade brasileira e muito menos para uma construção de uma cidadania mais plena.

Na matéria do site do Uol, dos 61 comentários registrados até o dia 5 de outubro de 2014, 28 eram contra a atitude de Neymar e a hashtag \#SomosTodosMacacos. Os personagens deste grupo não classificavam a campanha como um movimento contra o racismo, não se sentiam representados pela figura do macaco, criticavam a teoria da evolução de Darwin e a alienação dos brasileiros, apontando a questão da submissão aos países europeus. Os internautas que assinam como Leugula e Oluasaulo (figura 4), por exemplo, comentaram no site do Uol que a atitude do torcedor racista contra Daniel Alves não dava direito de Neymar chamá-lo de macaco e discordaram da campanha: 


\begin{abstract}
Leugula 6 meses atrás
Discordo do Neymar. Por favor me inclua fora disso. Se jogaram banana para o Daniel Alves para provocar, isto não dá o direito de me chamar de macaco. Não acho que sou macaco não. Digo isto porque sou contra este tipo de provocação, de racismo e por não me parecer em nada com este bicho que ele disse que é.

1 Penunciar

oluasaulo 6 meses atrás

Não somos macacos, tivemos sim o mesmo ancestral comum do animal chamado de macaco, então se bifurcou em dois seres distintos tal qual conhecemos como humanos e macacos, macacos não evoluirão a um dia ser um ser humano, ou vice versa,isso é inconteste, é Evolução. Logo pra mim não faz sentido algum os dizeres de Neymar de que somos macacos, alias não deveriam ligar pra isso, quanto mais ligam e dão atenção a este fato mais eles vão importunar, parece óbvio.
\end{abstract}

Figura 4: Comentários dos leitores do UOL.

Fonte: UOL (2014).

No dia 28 de abril de 2014, o jornalista Reinaldo Azevedo também publicou em seu blog, no site da Veja, uma matéria com o título "A aula de Daniel Alves e Neymar de combate ao racismo. Ou: Também sou macaco!". Nela, o jornalista publicou uma foto participando da campanha, em que também comia uma banana. A matéria teve 270 comentários até o dia 5 de outubro de 2014, mas muitos também eram contra o movimento criado pelo jogador Neymar nas redes sociais. Entre eles, o internauta Eduardo aponta a questão alienadora da mídia e o leitor Carlos (figura 5) representa o Brasil como país de terceiro mundo, destacando o estereótipo de o brasileiro levar tudo na brincadeira.

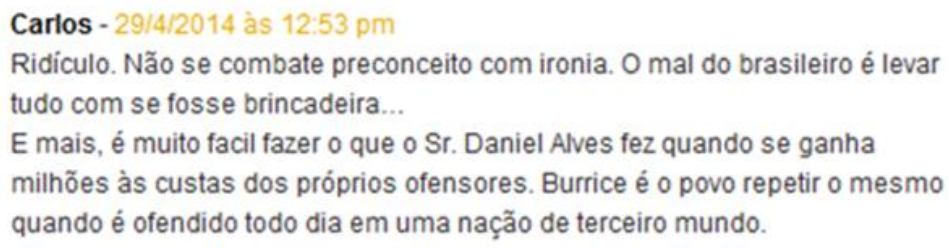

Figura 5: Comentário do leitor no site Veja.

Fonte: AZEVEDO (2014).

Em outra reportagem, desta vez no site do jornal Correio Braziliense, a professora da Faculdade de Educação da Universidade de Brasília (UnB), Renísia Cristina Garcia, também afirmou que não concordava com a ideia do jogador Neymar. Além disso, Renísia, que também é coordenadora do Núcleo de Estudos Afro-brasileiros (NEAB), afirmou na entrevista que a atitude de Daniel Alves resolvia apenas parte do problema racial. "A situação é recorrente, não só na Europa como no Brasil. Seria mais interessante se tivéssemos uma 
conscientização sobre onde nós guardamos o nosso racismo. No nosso cotidiano no Brasil temos várias manifestações racistas" (MACEDO, 2014).

O titular da Secretaria Especial da Promoção da Igualdade Racial do Distrito Federal (Sepir-DF), Viridiano Custódio, também avaliou a campanha como um reforço de um estereótipo que, segundo ele, o movimento negro brasileiro tenta combater há anos. Já a presidente do Brasil, Dilma Rousseff, elogiou o jogador Daniel Alves e deu total apoio a Neymar: "Ele lançou a campanha \#somostodosmacacos para mostrar que temos todos a mesma origem e que nada nos difere, a não ser nossa tolerância com o outro" (MACEDO, 2014).

\section{CONSIDERAÇÕES}

Ao mostramos alguns exemplos de como ocorreu a interação do público nas duas plataformas sociais de mídia - Instagram e site jornalístico - percebemos que o fato propiciou um debate democrático, com liberdade de expressão e crítica, onde os elementos formadores da identidade nacional ainda interferem no imaginário. No entanto, não podemos afirmar que a campanha "somos todos macacos" seja de fato uma representação coletiva da identidade brasileira, já que provocou no Brasil uma discussão dividida: de um lado os que sentiram representados pela representação criada por Neymar e de outro os que se sentiram excluídos e não aprovaram a maneira como o debate sobre racismo foi conduzido.

Do ponto de vista antropofágico, porém, o gesto do jogador Daniel Alves e a campanha criada pelo Neymar teve o componente simbólico de reafirmar nossa condição de povo novo, como defendido por Darcy Ribeiro, um povo que supera a pura questão da miscigenação a partir da construção de uma cidadania baseada na igualdade de direitos perante a lei. Somos todos macacos é uma expressão que deve ser explicada pela afirmação somos todos iguais segundo a lei.

\section{REFERÊNCIAS}

ANDRADE, Oswald. A Utopia antropofágica. São Paulo: Editora Globo, 2011. Manifesto da Poesia Pau-Brasil. Rio de Janeiro: Correio da Manhã, 1924. Obras completas: Do Pau-Brasil à Antropofagia e às utopias. Rio de Janeiro:

Civilização Brasileira, 1972. 
AZEVEDO, Reinaldo. A aula de Daniel Alves e Neymar de combate ao racismo. Ou: também sou macaco. Veja, 28/04/14. Disponível em: <http://veja.abril.com.br/blog/reinaldo/geral/a-aula-de-danielalves-e-neymar-de-combate-ao-racismo/>. Acesso em 29/09/10

DA MATTA, Roberto. O que faz o brasil, Brasil?. Rio de Janeiro: Rocco, 1986.

DÂMASO, Lívia. Brasileiros lideram ranking de horas gastas em redes sociais, diz estudo. Tech Tudo, 23/07/14. Disponível em: < http://www.techtudo.com.br/noticias/noticia/2014/07/brasileiroslideram-ranking-de-horas-gastas-em-redes-sociais-diz-estudo.html >. Acesso em 2/10/14

FRAGA, Nayara. Site do Instagram está entre os que mais cresceram no Brasil em julho. O Estadão, ago. 2012. Disponível em: <http://blogs.estadao.com.br/radar-tecnologico/2012/08/29/internetalcanca-834-milhoes-de-brasileiros/>. Acesso em: 07 jan. 2013.

G1. Instagram atinge marca de 200 milhões de usuários ativos por mês. 26/03/14. Disponível em: <http://g1.globo.com/tecnologia/tem-um-aplicativo/noticia/2014/03/instagram-atinge-marca-de-200milhoes-de-usuarios-ativos-por-mes.html>. Acesso em 5/10/14.

LADEIRA MOTA, Célia e ALMEIDA, Paulo. Jornalismo e redes sociais: identidade e cidadania. Publicado na revista eletrônica Eco-Pós. Rio de Janeiro: Editora da Universidade Federal do Rio de Janeiro, 2014.

MACEDO, Michelle. Somos todos macacos? Não, somos racistas, diz professora de estudos Afr. Correio Braziliense, 28/04/2014. Disponível em:

<http://www.correiobraziliense.com.br/app/noticia/cidades/2014/04/28/interna_cidadesdf,425124/som os-todos-macacos-nao-somos-racistas-diz-professora-de-estudos-afro.shtml>. Acesso em 29/09/10.

MOSCOVICI, Serge. Representações sociais: investigações em psicologia social. Petrópolis-RJ: Vozes, 2011.

RIBEIRO, Darcy. A América Latina existe? Rio de Janeiro: Fundação Darcy Ribeiro e Editora Universidade de Brasília, 2010.

THOMPSON, John B. Ideologia e cultura moderna: teoria social crítica na era dos meios de comunicação de massa. Petrópolis- RJ: Vozes, 1995.

UOL. Neymar apoia Dani Alves após lateral comer banana: somos todos macacos. 27/04/14. Disponível em: <http://esporte.uol.com.br/futebol/ultimas-noticias/2014/04/27/neymar-apoia-danialves-apos-lateral-comer-banana--toma-bando-de-racista.htm>. Acesso em 5/10/14.

Original recebido em: 09/01/2015

Aceito para publicação em: 04/12/15

Célia Maria Ladeira Mota

Jornalista, Doutora em Comunicação e pesquisadora associada ao Programa de PósGraduação da Faculdade de Comunicação da Universidade de Brasília (UnB). Pertence aos grupos de pesquisa Jornalismo e Construção Narrativa da História do Presente; Cultura, Mídia e Política; e Núcleo de Mídia e Política (NEMP), da UnB. [cladmota@gmail.com] 
Paulo Henrique Soares de Almeida

Jornalista, Mestre em Comunicação pela Universidade de Brasília (UnB) e especialista em Leitura e Produção de Texto pela Universidade Católica de Brasília (UCB). Pertence aos grupos de pesquisa Jornalismo e Construção Narrativa da História do Presente e Cultura, Mídia e Política, da UnB. [Pauloalmmeida@gmail.com] 